\title{
Different outcomes of phonemic verbal fluency in Parkinson's disease patients with subthalamic nucleus deep brain stimulation
}

\author{
Diferentes desfechos na tarefa de fluência verbal fonêmica em pacientes com doença de
} Parkinson submetidos à estimulação cerebral profunda Aline Juliane Romann', Bárbara Costa Beber ${ }^{1,2}$, Maira Rozenfeld Olchik ${ }^{1,3}$, Carlos R M. Rieder ${ }^{1,4,5}$

\begin{abstract}
Subthalamic nucleus deep brain stimulation (STN-DBS) is a surgical technique to treat motor symptoms in patients with Parkinson's disease (PD). Studies have shown that STN-DBS may cause a decline in verbal fluency performance. We aimed to verify the effects of STN-DBS on the performance of phonemic verbal fluency in Brazilian PD patients. Sixteen participants were evaluated on the Unified Parkinson's Disease Rating Scale - Part III and for phonemic fluency ("FAS" version) in the conditions of on- and off-stimulation. We identified two different patterns of phonemic verbal fluency outcomes. The results indicate that there may be no expected pattern of effect of bilateral STN-DBS in the phonemic fluency, and patients may present with different outcomes for some reason not well understood.
\end{abstract}

Keywords: Parkinson disease; deep brain stimulation; language; cognition.

RESUMO

A estimulação cerebral profunda do núcleo subtalâmico (ECP-NST) é uma técnica cirúrgica para tratar sintomas motores na doença de Parkinson (DP). Estudos têm mostrado que ECP-NST pode causar um declínio no desempenho de fluência verbal. O objetivo do estudo foi verificar os efeitos da ECP-NST sobre o desempenho da fluência verbal fonêmica em indivíduos brasileiros com DP. Dezesseis participantes foram avaliados quanto ao desempenho motor (UPDRS-III) e à fluência verbal fonêmica (versão “FAS") nas condições de estimulação ligada e desligada. Identificamos dois padrões diferentes de resultados de fluência verbal fonêmica. Os resultados indicam que pode não haver um padrão esperado de efeito de ECP-NST bilateral na fluência fonêmica, e os pacientes podem apresentar desfechos diferentes de acordo com alguma razão não bem compreendida.

Palavras-chave: doença de Parkinson; estimulação encefálica profunda; linguagem; cognição.

Subthalamic nucleus deep brain stimulation (STN-DBS) is a procedure used to treat patients with Parkinson's disease (PD) when pharmacological treatment is no longer efficient ${ }^{1}$. It has been proven that DBS suppresses motor symptoms and reduces the total dose of the antiparkinsonian drugs ${ }^{2,3}$.

Among the adverse effects of STN-DBS in patients with $\mathrm{PD}$, the postoperative decline in verbal fluency is well documented ${ }^{4,5,6,7,8,9,10,11}$. However, there are fewer studies about the effect of the stimulation per se, comparing on- and off- stimulation conditions ${ }^{12,13,14}$. Longitudinal studies verified a worsening of verbal fluency in the first months after surgery, but an improvement in the later studied months ${ }^{9}$. These authors suggest that this effect of the DBS on the verbal fluency may be due to the micro-lesions caused by the implantation procedure of the electrodes in the STN.

The verbal fluency test evaluates the capacity to search and retrieve data stored in long-term memory within a certain category and demonstrates the capacities of

\footnotetext{
${ }^{1}$ Universidade Federal do Rio Grande do Sul, Programa de Pós Graduação em Medicina: Ciências Médicas, Porto Alegre RS, Brasil;

${ }^{2}$ Faculdade Nossa Senhora de Fátima, Faculdade de Fonoaudiologia, Caxias do Sul RS, Brasil;

${ }^{3}$ Universidade Federal do Rio Grande do Sul, Faculdade de Odontologia, Porto Alegre RS, Brasil;

${ }^{4}$ Hospital de Clínicas de Porto Alegre, Serviço de Neurologia, Porto Alegre RS, Brasil;

${ }^{5}$ Universidade Federal Ciências da Saúde, Porto Alegre RS, Brasil.
}

Correspondence: Carlos R. M. Rieder; Rua Ramiro Barcelos, 2350 / sala 2040; 90035-903 Porto Alegre RS, Brasil; E-mail: carlosrieder@gmail.com

Conflict of interest: There is no conflict of interest to declare.

Support: Fundo de Incentivo à Pesquisa e Eventos (FIPE), Hospital de Clínicas de Porto Alegre (HCPA).

Received 08 November 2016; Accepted 06 January 2017. 
organization, self-regulation and operational memory. This instrument offers three main variations: phonemic fluency, semantic fluency, and action or verb fluency ${ }^{15,16}$. Each type of verbal fluency task may offer specific information regarding cognition, given that each one requires access to specific lexical and/or semantic representations according to the criteria used. The verbal fluency tasks activate overlapping areas of the frontal brain regions, but different word retrieval criteria likely activate additional distinct regions ${ }^{16}$. Executive dysfunction is the predominant profile of cognitive impairment in patients with PD, and phonemic fluency may be a good type of verbal fluency task to evaluate this population because the executive deficit is associated with frontal-lobe dysfunction ${ }^{17}$. Furthermore, PD may be a good neural model to study the principles of subcortical lexical processing, and studies in different cultural settings may enrich the theoretical framework about this issue as well.

It is important to understand the effects of STN-DBS on the patient's language to adequately manage the treatments (speech therapy, cognitive training, pharmacological treatments, adjustment of the stimulator) and to improve quality of life. Thus, this study aimed to verify the effects of STN-DBS on the performance of phonemic verbal fluency in Brazilian PD patients.

\section{METHODS}

\section{Participants}

Brazilian patients with PD who had undergone bilateral STN-DBS were selected from the Movement Disorder Clinic at Hospital de Clínicas de Porto Alegre. Exclusion criteria were: a poor response to the procedure, presence of another neurological condition (e.g., stroke, dementia), and not being a native speaker of Brazilian Portuguese. The study was approved by the local ethics committee (No. 10.0508) and all participants gave written informed consent.

\section{Instruments and procedures}

Clinical and demographic data were obtained from the patient's records to describe the sample. The assessment team consisted of one movement disorder neurologist, and three speech and language therapists.

Cognitive screening was carried out using the Mini-Mental State Examination (MMSE) and Montreal Cognitive Assessment (MoCA) at the start as a baseline, using the adapted version for Brazilian population ${ }^{18,19}$.

Motor function was assessed using the Unified Parkinson's Disease Rating Scale (UPDRS) part III (maximum score of 108 points).

Verbal fluency was assessed by the FAS test for phonemic verbal fluency ${ }^{20}$. The participants were asked to say as many words as possible that started with the letters
"F", "A" and "S" during one minute for each letter. Proper names, numbers, the same word with different suffix or different verb conjugations were excluded. The final score was the sum of all correct words.

The UPDRS-III and the phonemic verbal fluency assessments were performed on the same day with patients on their usual antiparkinsonian medication, in the following conditions: 1) on-stimulation: the patients were evaluated with the DBS turned on and adjusted for the best symptom control by each patient (baseline); 2) off-stimulation: the DBS was turned off and the assessments were carried out after 60 minutes or until the patient could not tolerate the symptoms. At the end of the off-stimulation evaluation, the DBS was turned on again.

\section{Statistical analysis}

Statistical analyses were performed using the Statistical Package for Social Sciences (SPSS version 21.0) with a significance level of $5 \%$ ( $p \leq 0.05)$. Continuous variables were reported as the mean and standard deviation. Categorical variables were described by the absolute and relative frequencies.

To compare the phonemic fluency and UPDRS-III performances between on- and off-stimulation conditions we used the Wilcoxon signed ranking test. We calculated the delta value to verify the change in the phonemic verbal fluency (on-stimulation total score minus off-stimulation total score). The participants were split into two groups, according to the percentile of delta values: "improvement in on-stimulation", and "worsening in on-stimulation". The variables of: age in years, education in years, MMSE, MoCA, years after diagnosis, months after surgery, UPDRS-III in on- and off-stimulation, voltage, frequency, and pulse of DBS, were compared between the groups "improvement with on-stimulation", and "worsening with on-stimulation" using the Mann-Whitney U test or the Chi-square test. Correlations were verified with the Spearman's correlation test.

\section{RESULTS}

Sixteen Brazilian PD patients were included in the study. Three participants did not tolerate the motor symptoms during the off-stimulation condition and were not able to complete the evaluation at that time. Table 1 shows the descriptive data of the participants.

We compared the performance of the phonemic verbal fluency between on- and off stimulation conditions and it showed no statistical difference $(\mathrm{p}=0.168)$. On the other hand, the scores on the UPDRS were significantly worse in the off-stimulation period ( $\mathrm{p}<0.000)$.

When we observed the performance of patients individually, we realized that they presented diverse patterns of 
outcomes after the DBS had been turned off(Figure A). Some participants seemed to improve, others worsened and others showed no difference, which made us realize that we could divide the participants into different groups according to their performance and evaluate these on their different outcomes. To do this, we calculated the delta value of phonemic fluency and, based on the percentiles of the delta values, we split the participants into two groups, which were named: "improvement with DBS on" ( $\mathrm{n}=5)$, and "worsening with DBS on" $(\mathrm{n}=8)$ (Figure B).

We compared the demographic (sex, age, education), cognitive (MMSE, MoCA, delta of phonemic verbal fluency) and clinical variables (years after diagnosis; months after surgery; delta of UPDRS-III; voltage, frequency, and pulse of DBS) between the groups "improvement with on-stimulation" and "worsening with on-stimulation" and there was no statistical difference for any variable, except for phonemic verbal fluency (Table 2). As expected, the delta of phonemic fluency was statistically different between groups.

Furthermore, we tested the correlation between the delta of phonemic verbal fluency and all the studied variables in the full sample. There was no correlation between phonemic verbal fluency and any variable (age: $r=0.42, p=0.15$; education: $r=-0.05, p=0.87 ;$ MMSE: $r=-0.17, p=0.62$; MoCA: $r=-0.35$, $\mathrm{p}=0.26$; years after diagnosis: $\mathrm{r}=0.04, \mathrm{p}=0.91$; months after surgery: $r=-0.05, p=0.88$; voltage $R: r=-0.21, p=0.50$;

Table 1. Descriptive data of participants $(n=16)$.

\begin{tabular}{|c|c|}
\hline Variable & $\mathrm{M}(\mathrm{SD})$ or $\mathrm{N}(\%)$ \\
\hline Gender - male & $12(75 \%)$ \\
\hline Education & $12.06(4.20)$ \\
\hline Years after diagnosis & $12.31(4.03)$ \\
\hline Months after surgery & $23.88(13.38)$ \\
\hline MMSE & $24.29(5.18)$ \\
\hline $\mathrm{MoCa}$ & $19.27(5.75)$ \\
\hline \multicolumn{2}{|l|}{ UPDRS-III } \\
\hline On-stimulation & $24.19(11.07)$ \\
\hline Off-stimulation & $37.77(15.37)$ \\
\hline \multicolumn{2}{|l|}{ Voltage (v) } \\
\hline Left & $29.75(5.5 .6)$ \\
\hline Right & $27.75(8.89)$ \\
\hline \multicolumn{2}{|l|}{ Frequency $(\mathrm{Hz})$} \\
\hline Left & $156.25(29.92)$ \\
\hline Right & $156.25(29.92)$ \\
\hline \multicolumn{2}{|l|}{ Pulse width (ls) } \\
\hline Left & $84.38(19.65)$ \\
\hline Right & $90.00(18.97)$ \\
\hline \multicolumn{2}{|l|}{ Phonemic verbal fluency } \\
\hline On-stimulation & $28.00(12.03)$ \\
\hline Off-stimulation & $26.75(13.94)$ \\
\hline Delta of phonemic verbal fluency & $1.25(8.41)$ \\
\hline
\end{tabular}

voltage $\mathrm{L}: \mathrm{r}=-0.19, \mathrm{p}=0.54$; frequency $\mathrm{R}: \mathrm{r}=0.06, \mathrm{p}=0.85$; frequency $L: r=0.06, p=0.085$; pulse $R: r=-0.40 p=0.19$; pulse L: $r=-0.11, p=0.73$; delta of UPDRS-III: $r=-0.07, p=0.82$ ).

\section{DISCUSSION}

This study verified the effect of STN-DBS on the performance of phonemic verbal fluency in a sample of Brazilian PD patients, testing the phonemic fluency in on- and off-stimulation conditions. The phonemic verbal fluency did not differ between on and off conditions, however when participants
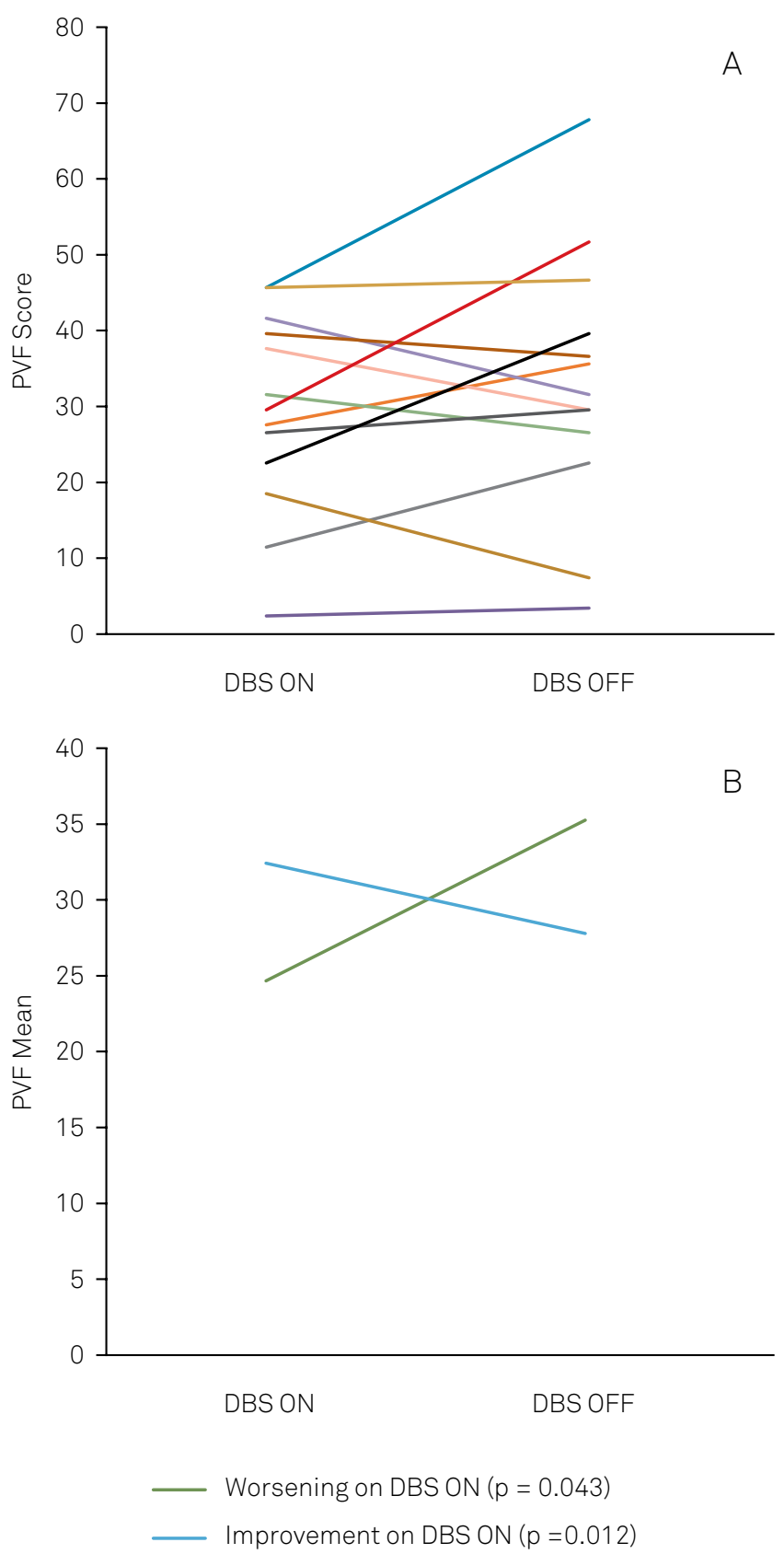

A: Individual performance. B: Group performance.

Figure. Performance on phonemic verbal fluency (PVF) in the on- and off-stimulation conditions. 
Table 2. Descriptive data and comparisons between groups "improvement with DBS on" and "worsening with DBS on".

\begin{tabular}{|c|c|c|c|}
\hline \multirow{2}{*}{ Variable } & $\begin{array}{c}\text { Improvement } \\
\text { with DBS on } \\
\end{array}$ & $\begin{array}{c}\text { Worsening } \\
\text { with DBS on }\end{array}$ & \multirow[t]{2}{*}{$\mathrm{p}$} \\
\hline & $(n=5)$ & $(n=8)$ & \\
\hline Gender-male & $1(20 \%)$ & $2(25 \%)$ & 1.00 \\
\hline Age & $63.00(11.31)$ & $57.38(12.88)$ & 0.52 \\
\hline Education & $12.00(5.10)$ & $12.38(4.37)$ & 1.00 \\
\hline Years after diagnosis & $12.20(4.38)$ & $12.25(4.59)$ & 1.00 \\
\hline Months after surgery & $25.20(17.18)$ & $24.38(13.46)$ & 1.00 \\
\hline MMSE & $23.80(5.26)$ & $23.67(6.38)$ & 1.00 \\
\hline MoCA & $17.40(6.84)$ & $19.43(5.91)$ & 0.64 \\
\hline \multicolumn{4}{|l|}{ Voltage (v) } \\
\hline Left & $28.20(5.93)$ & $28.75(5.37)$ & 1.00 \\
\hline Right & $27.20(5.07)$ & $29.12(6.71)$ & 0.62 \\
\hline \multicolumn{4}{|l|}{ Frequency $(\mathrm{Hz})$} \\
\hline Left & $152.00(31.14)$ & $148.12(30.23)$ & 0.72 \\
\hline Right & $152.00(31.14)$ & $148.12(30.23)$ & 0.72 \\
\hline \multicolumn{4}{|l|}{ Pulse width (Is) } \\
\hline Left & $78.00(16.43)$ & $78.75(15.53)$ & 1.00 \\
\hline Right & $84.00(13.41)$ & $86.25(19.23)$ & 1.00 \\
\hline Delta of UPDRS & $13.80(6.56)$ & $15.12(7.68)$ & 0.62 \\
\hline Delta of phonemic VF & $7.40(3.36)$ & $-10.62(8.86)$ & $0.002 *$ \\
\hline
\end{tabular}

M: mean; SD: standard deviation; DBS: deep brain stimulation; VF: verbal fluency; MMSE: Mini-Mental State Examination; MoCa: Montreal Cognitive Assessment; UPDRS: Unified Parkinson's Disease Rating Scale. ${ }^{\star} p £ 0.05$, Chi-square or Mann-Whitney U test.

where individually observed we found two different outcomes in effect: in one group the phonemic verbal fluency improved when DBS was on, while in the other group it worsened.

The improvement of motor patterns in the presence of DBS stimulation is already a consensus ${ }^{1,21}$. Also, the majority of previous studies pointed to a negative effect of STN-DBS on verbal fluency when they studied postsurgical patients ${ }^{22}$. Some of the studies on pre- and post-DBS have found a decline in phonemic fluency ${ }^{5,7,10}$, others a decline in semantic fluency ${ }^{6}$ and still others in both verbal fluency tasks ${ }^{4,8,9}$.
However, the studies comparing verbal fluency performance between pre- and postsurgical periods may reflect the surgery consequences more than the stimulation per se. The comparison between on- and off- conditions of DBS may be more indicative of the effect of the stimulation. Some previous studies using this approach found no differences in phonemic verbal fluency ${ }^{12,13,14,23}$, corroborating our analysis with the full sample, in which we did not find any effect of DBS on the phonemic fluency, despite finding a positive effect of the stimulation on the motor function.

The results that showed a decline in verbal fluency postsurgery and those that found an absence of effect of stimulation in the on-condition point to the hypothesis that verbal fluency deficits may not be caused by the electrical stimulation but rather by the surgery or the evolution of PD. In our study, we found that the neurostimulation increased the verbal fluency performance in one group of PD patients while it was impaired in another, which contradicts the previous hypothesis. Furthermore, any of the demographic, clinical, cognitive variables and parameters of STN-DBS may be able to explain the different outcomes. The data of a previous study suggested that the stimulation effect may depend on the locus and volume of activated tissue $e^{24}$, which was not investigated in our study and may be a hypothesis for our findings.

Our results should be interpreted with consideration of some limitations, such as the small sample size and the fact that three participants did not perform the task in the off-stimulation period. Despite this, our study indicates that there may be no unique pattern from the effect of bilateral STN stimulation on phonemic verbal fluency, and patients may present with different outcomes according to some reason that is not well understood. It is necessary to understand what leads to different outcomes to improve patient management and understand which subcortical pathways are involved in lexical access. Future studies should analyze the different outcomes of verbal fluency in STN stimulation in bigger samples, using diverse tasks, i.e. semantic and verb fluency, and to verify the association with the lead and localization of the electrodes.

\section{References}

1. Fox SH, Katzenschlager R, Lim SY, Ravina B, Seppi K, Coelho M et al. The Movement Disorder Society Evidence-Based Medicine Review Update: treatments for the motor symptoms of Parkinson's disease. Mov Disord. 2011;26(Suppl 3):S2-41 https://doi.org/10.1002/mds.23829

2. Alberts JL, Voelcker-Rehage C, Hallahan K, Vitek M, Bamzai $\mathrm{R}$, Vitek JL. Bilateral subthalamic stimulation impairs cognitive-motor performance in Parkinson's disease patients. Brain. 2008;131(12):3348-60. https://doi.org/10.1093/brain/awn238

3. Greenhouse I, Gould S, Houser M, Hicks G, Gross J, Aron AR. Stimulation at dorsal and ventral electrode contacts targeted at the subthalamic nucleus has different effects on motor and emotion functions in Parkinson's disease. Neuropsychologia. 2011;49(3):528-34. https://doi.org/10.1016/j.neuropsychologia.2010.12.030

4. Castelli L, Perozzo P, Zibetti M, Crivelli B, Morabito U, Lanotte M et al. Chronic deep brain stimulation of the subthalamic nucleus for
Parkinson's disease: effects on cognition, mood, anxiety and personality traits. Eur Neurol. 2006;55(3):136-44. https://doi.org/10.1159/000093213

5. Castelli L, Lanotte M, Zibetti M, Caglio M, Rizzi L, Ducati A et al. Apathy and verbal fluency in STN-stimulated PD patients: an observational follow-up study. J Neurol. 2007;254(9):1238-43. https://doi.org/10.1007/s00415-006-0510-7

6. Cilia R, Siri C, Marotta G, De Gaspari D, Landi A, Mariani CB et al. Brain networks underlining verbal fluency decline during STN-DBS in Parkinson's disease: an ECD-SPECT study. Parkinsonism Relat Disord. 2007;13(5):290-4. https://doi.org/10.1016/j.parkreldis.2006.11.011

7. Contarino MF, Daniele A, Sibilia AH, Romito LM, Bentivoglio AR, Gainotti $\mathrm{G}$ et al. Cognitive outcome 5 years after bilateral chronic stimulation of subthalamic nucleus in patients with Parkinson1s disease. J Neurol Neurosurg Psychiatry. 2007;78(3):248-52. https://doi.org/10.1136/jnnp.2005.086660 
8. De Gaspari D, Siri C, Di Gioia M, Antonini A, Isella V, Pizzolato A et al. Clinical correlates and cognitive underpinnings of verbal fluency impairment after chronic subthalamic stimulation in Parkinson's disease. Parkinsonism Relat Disord. 2006;12(5):289-95. https://doi.org/10.1016/j.parkreldis.2006.01.001

9. Lefaucheur R, Derrey S, Martinaud O, Wallon D, Chastan N, Gérardin E et al. Early verbal fluency decline after STN implantation: is it a cognitive microlesion effect? J Neurol Sci. 2012;321(1-2):96-9. https://doi.org/10.1016/j.jns.2012.07.033

10. Sáez-Zea C, Escamilla-Sevilla F, Katati MJ, Mínguez-Castellanos A. Cognitive effects of subthalamic nucleus stimulation in Parkinson's disease: a controlled study. Eur Neurol. 2012;68(6):361-6. https://doi.org/10.1159/000341380a

11. Aono M, Iga J, Ueno S, Agawa M, Tsuda T, Ohmori T. Neuropsychological and psychiatric assessments following bilateral deep brain stimulation of the subthalamic nucleus in Japanese patients with Parkinson's disease. J Clin Neurosci. 2014;21(9):1595-8. https://doi.org/10.1016/j.jocn.2013.12.020

12. Witt K, Pulkowski U, Herzog J, Lorenz D, Hamel W, Deuschl $G$ et al. Deep brain stimulation of the subthalamic nucleus improves cognitive flexibility but impairs response inhibition in Parkinson disease. Arch Neurol. 2004;61(5):697-700. https://doi.org/10.1001/archneur.61.5.697

13. Ehlen F, Krugel LK, Vonberg I, Schoenecker T, Kühn AA, Klostermann F. Intact lexicon running slowly: prolonged response latencies in patients with subthalamic DBS and verbal fluency deficits. PLoS One. 2013;8(11):e79247 https://doi.org/10.1371/journal.pone.0079247

14. Tremblay C, Macoir J, Langlois M, Cantin L, Prud'homme M, Monetta L. The effects of subthalamic deep brain stimulation on metaphor comprehension and language abilities in Parkinson's disease. Brain Lang. 2015;141:103-9. https://doi.org/10.1016/j.bandl.2014.12.004

15. Strauss E, Sherman E, Spreen O. Executive Functions. A Compendium of neuropsychological tests: administration, norms, and commentary. 3rd ed. Oxford: Oxford University Press; 2006. p. 499-525.
16. Pekkala, S. Verbal fluency tasks and the neuropsychology of language. In: Faust M, ed. The Handbook of the neuropsychology of language. Oxford:Wiley-Blackwell; 2012. p. 619-34.

17. Schwartz S, Baldo J, Graves RE, Brugger P. Pervasive influence of semantics in letter and category fluency: a multidimensional approach. Brain Lang. 2003;87(3):400-11. https://doi.org/10.1016/S0093-934X(03)00141-X

18. Brucki SM, Nitrini R, Caramelli P, Bertolucci PH, Okamoto IH. [Suggestions for utilization of the mini-mental state examination in Brazil]. Arq Neuropsiquiatr. 2003;61(3B):777-81. Portuguese. https://doi.org/10.1590/S0004-282X2003000500014

19. Sarmento ALR. Apresentação e aplicabilidade da versão brasileira da MoCA (Montreal cognitive assessment) para rastreio de comprometimento cognitivo leve (MD). São Paulo: Escola Paulista de Medicina da Universidade Federal de São Paulo; 2009.

20. Machado TH, Fichman HC, Santos EL, Carvalho VA, Fialho PP, Koenig AM et al. Normative data for healthy elderly on the phonemic verbal fluency task - FAS. Dement Neuropsychol. 2009;3(1) 55-60. https://doi.org/10.1590/S1980-57642009DN30100011

21. Moldovan AS, Groiss SJ, Elben S, Südmeyer M, Schnitzler A, Wojtecki L. The treatment of Parkinson's disease with deep brain stimulation: current issues. Neural Regen Res. 2015;10(7):1018-22. https://doi.org/10.4103/1673-5374.160094

22. Wyman-Chick KA. Verbal fluency in Parkinson's patients with and without bilateral deep brain stimulation of the subthalamic nucleus: a meta-analysis. J Int Neuropsychol Soc. 2016;22(4):478-85. https://doi.org/10.1017/S1355617716000035

23. Ehlen F, Schoenecker T, Kühn AA, Klostermann F. Differential effects of deep brain stimulation on verbal fluency. Brain Lang. 2014;134:23-33. https://doi.org/10.1016/j.bandl.2014.04.002

24. Mikos A, Bowers D, Noecker AM, McIntyre CC, Won M, Chaturvedi A et al. Patient-specific analysis of the relationship between the volume of tissue activated during DBS and verbal fluency. Neuroimage. 2011;54 Suppl 1:S238-46. https://doi.org/10.1016/j.neuroimage.2010.03.068 